\title{
Communally breeding bats use physiological and behavioural adjustments to optimise daily energy expenditure
}

\author{
Iris Pretzlaff • Gerald Kerth • Kathrin H. Dausmann
}

Received: 9 November 2009/Revised: 30 December 2009 / Accepted: 4 January 2010/Published online: 9 February 2010

(C) The Author(s) 2010. This article is published with open access at Springerlink.com

\begin{abstract}
Small endotherms must change roosting and thermoregulatory behaviour in response to changes in ambient conditions if they are to achieve positive energy balance. In social species, for example many bats, energy expenditure is influenced by environmental conditions, such as ambient temperature, and also by social thermoregulation. Direct measurements of daily fluctuations in metabolic rates in response to ambient and behavioural variables in the field have not been technologically feasible until recently. During different reproductive periods, we investigated the relationships between ambient temperature, group size and energy expenditure in wild maternity colonies of Bechstein's bats (Myotis bechsteinii). Bats used behavioural and physiological adjustments to regulate energy expenditure. Whether bats maintained normothermia or used torpor, the number of bats in the roosts as well changed with reproductive status and ambient temperature. During pregnancy and lactation, bats remained mostly normothermic and daily group sizes were relatively large, presumably to participate in the energetic benefits of social thermoregulation. In contrast, smaller groups were formed on
\end{abstract}

I. Pretzlaff $(\bowtie) \cdot$ K. H. Dausmann

Department of Animal Ecology and Conservation,

Biocentre Grindel, University of Hamburg,

Martin-Luther-King Platz 3,

20146 Hamburg, Germany

e-mail: iris.pretzlaff@gmx.de

G. Kerth

Zoologisches Institut, Universität Zürich,

Winterthurerstr. 190,

8057 Zürich, Switzerland

G. Kerth

Max-Planck-Institute for Ornithology,

82319 Seewiesen, Germany days when bats used torpor, which occurred mostly during the post-lactation period. Thus, we were able to demonstrate on wild animals under natural conditions the significance of behavioural and physiological flexibility for optimal thermoregulatory behaviour in small endotherms.

Keywords Bechstein's bats · Ecophysiology · Group size · Reproduction · Respirometry $\cdot$ Social thermoregulation

\section{Introduction}

The energetic costs of life are high for small endotherms such as rodents, bats or birds, especially when ambient temperature $\left(T_{\mathrm{a}}\right)$ is low. Moreover, in many small mammals, such as bats, energy demands are particularly high during pregnancy or lactation (Gittleman and Thompson 1988). One way how many bats are able to save energy is through the use of torpor which is characterised by a controlled, substantial drop in metabolic rate (MR) and body temperature ( $T_{\mathrm{b}}$; Heldmaier and Ruf 1992; Geiser and Ruf 1995). In addition to hibernation (prolonged torpor bouts; $>24 \mathrm{~h}$ ) during winter, temperate zone bats often become torpid during periods of cold weather in summer (daily torpor) to save energy (e.g. Davis 1970; Grinevitch et al. 1995). However, by reducing MR, torpor prolongs gestation length (Racey 1973; Racey and Swift 1981; Lewis 1993) and impairs lactation (Wilde et al. 1999). The resulting late births and slow juvenile growth rates reduce the probability for juveniles to survive their first winter as there may not be enough time to accumulate sufficient fat prior to hibernation (McNab 1982; Ransome 1989). Thus, reproductive female bats may profit from minimising torpor use despite energetic disadvantages for them from staying normothermic (but see Willis et al. 2006). 
There are other ways in which bats may optimise their energetic balance other than entering torpor. Females of most temperate zone bats form maternity colonies during summer to communally rear pups (Kerth 2008). These colonies allow individuals to reduce heat loss by forming a cluster and therefore by their behaviour (social thermoregulation), which improves insulation and thus results in considerable energy savings (e.g. Herreid 1963; Roverud and Chappell 1991; Hayes et al. 1992; Boyles et al. 2008). To optimise social thermoregulation, colony members can vary group size during the reproductive season (Eptesicus fuscus; Lausen and Barclay 2002) or with changing ambient conditions. For example, female Myotis evotis, which typically roosted alone when pregnant, will form small colonies during lactation when $T_{\mathrm{a}}$ is low (Solick and Barclay 2006). Additionally, individuals may select roosts based on microclimate for a given day, as shown for Bechstein's bat (Kerth et al. 2001) and other species (Vaughan and O'Shea 1976; Sedgeley 2001; Chruszcz and Barclay 2002; Solick and Barclay 2006).

Group size, $T_{\mathrm{a}}$ and reproductive status all should crucially influence energy balance of temperate zone bats (Willis and Brigham 2007). However, little is known regarding the dependency of energy budgets of bats on group size, reproductive status and $T_{\mathrm{a}}$ under field conditions because direct, continuous measurements of MR in the field have only recently become technologically feasible. The few studies regarding the ecophysiology of wild bats either used indirect methods such as temperature telemetry (e.g. Dietz and Kalko 2006) to infer MR or combined measurements of roost temperature $\left(T_{\text {roost }}\right)$ and group size in the field with laboratory measurements of MR, $T_{\mathrm{b}}$ and $T_{\text {roost }}$ to estimate energy budgets (Willis and Brigham 2007). Alternatively, they used doubly labelled water to measure total daily energy expenditure (Speakman and Racey 1987; Kurta et al. 1990; McLean and Speakman 1999; Korine et al. 2004), but which cannot distinguish daily fluctuations in MR in relation to changing group sizes and $T_{\mathrm{a}}$ in the field.

Although these approaches increase our knowledge of bat ecophysiology, they rely mostly on the assumption that results from captive studies can be extrapolated to wild animals. However, such an extrapolation may be especially critical for mammals and birds that use torpor because patterns of energy expenditure during torpor differ markedly between captive and wild animals (Geiser et al. 2000). Moreover, physiological variables can be much more flexible within a species than previously thought (Dausmann et al. 2009), particularly in times of energetic stress such as periods of food shortage and adverse weather. Because animals can often only employ the whole spectrum of their physiological and behavioural capabilities in the field, investigating physiological and behavioural adjustments of energy expenditure in wild bats is needed to understand the advantages of sociality in bats and the plasticity of their physiological traits.

The aim of our study was to investigate the ecophysiology of communally roosting Bechstein's bats during different periods (pre-lactation, lactation and post-lactation) of their reproductive cycle by measuring MR (energy expenditure) using respirometry in wild bats. Maternity colonies of Bechstein's bats regularly split into subgroups of variable size (fission-fusion behaviour), and they may occupy up to 50 different roosts (tree cavities and bat boxes) during one breeding season (Kerth and König 1999). To establish the links between MR, $T_{\mathrm{a}}$, reproductive state and group size in wild bats, we specifically aimed to answer the following questions: What are the patterns of energy expenditure during pre-lactation, lactation and post-lactation? How does the frequency of torpor use differ between these periods? Does $T_{\mathrm{a}}$ influence group size during any one particular reproductive period? Does $T_{\mathrm{a}}$ and group size influence MR? We hypothesised that bats use torpor more frequently during periods of cold weather as torpor use leads to a strong reduction in MR and thus helps the bats to save energy. We expected that low $T_{\mathrm{a}}$ as well as roosting in small groups increase MR in normothermic bats or result in substantial energy savings due to torpor use. Because torpor, particularly for reproductive females, also has disadvantages such as a delayed offspring development (Geiser 1996), we finally hypothesised the bats to use torpor less often during the pre-lactation and lactation than during the post-lactation period.

\section{Materials and methods}

Study animal and study site

The insectivorous Bechstein's bat occurs in the temperate and subtropical zones of Europe. Females appear from hibernation near the end of April in their summer habitat (forest) where they communally breed in socially closed maternity colonies (strong female philopatry and almost no immigration from neighbouring colonies); males are solitary (Kerth et al. 2000). Colonies comprise reproductive and non-reproductive females; approximately two thirds of the adult females give birth to a single pup in a given year (Kerth and König 1999). Near the end of September, Bechstein's bats leave the summer habitat (the place of hibernation is not known; Kerth and König 1999). Data were collected from two maternity colonies ("Blutsee" and "Guttenberg 2") that roost in adjacent deciduous forests, both of which are located approximately $15 \mathrm{~km}$ southwest of Würzburg, Germany. Both colonies roost largely in bat boxes (type: Schwegler 2FN, Schwegler GmbH, Germany). All adult females were individually marked with passive 
integrated transponders (Trovan ${ }^{\circledR}$ Euro I.D. Weilerswist, Germany; Kerth and Reckardt 2003).

\section{Climate data}

Data on daily minimum, maximum and mean $T_{\mathrm{a}}$ were provided by a nearby meteorological station (Landesamt für Wald-und Forstwirtschaft). In spring 2006, we equipped bat boxes and five tree cavities that were known roost sites in previous years with temperature loggers (DS1922L Thermochron ${ }^{\circledR}$ iButtons, Dallas Semiconductor, Dallas, USA, resolution $\pm 0.5^{\circ} \mathrm{C}$ ) for continuous measurements of $T_{\text {roost }}$. In each box, we adhered an iButton inside under the roof which is the preferred roosting site. To obtain the temperature of the immediate vicinity of the roost site $\left(T_{\text {out }}\right)$, a second iButton was attached to the tree trunk (mounting type: DS9093F plastic snap-in key fob, Dallas Semiconductor) so that it recorded $T_{\text {out }}$ next to the bat box in the shade. The fob itself was attached to the tree by a cotton thread and a drawing pin. All iButtons were programmed to record temperature once per hour.

Roosting behaviour, body mass and reproductive status of the colony members

In both colonies, all bat boxes $(N=189)$ and five tree cavities that were known roost sites were checked for present bats daily from 22 April to 27 September 2006 . Because bat box entrances face the ground, roosting bats can be seen with a torch without opening the box and disturbing the bats (bats showed no visible or audible reaction (listening for squeaks and clicks without bat detector) to the roost checks). To find bats in tree cavities, we used a mobile reading device (Trovan ${ }^{\circledR}$ Euro I.D. Weilerswist, Germany; maximal reading distance $15 \mathrm{~cm}$ ). When we found bats in a bat box, we installed an automatic transponder reader to continuously monitor departure and arrival of bats (Kerth and Reckardt 2003). With this method, we were able to determine group size and individual group composition in different day roosts over 152 consecutive days. Group size in a roost generally refers to adult females because the juveniles have not yet been pittagged to avoid any risk to their survival. However, one aim of our study was to analyse how group size affects $T_{\text {roost }}$. To estimate the possible influence of juveniles on $T_{\text {roost }}$, we considered juveniles as adults from day 23 after birth. The first 4 days after birth, juveniles are naked and presumably still poikilotherm (Weigold 1973; Hollis and Barclay 2008). Therefore, we estimated their presence from day 5 to day 22 after birth with growth as described further below. All bats were captured by hand twice from bat boxes to measure their body mass and determine their reproductive status. These measurements were made once in the third week of May (before parturition) and again near the end of the lactation period, in the second week of August. In August, females with enlarged nipples, surrounded by an area of furless skin, were classified as lactating. We divided our study period into three periods corresponding to the reproductive status of the females: pre-lactation (before parturition: 22 April-16 June 2006), lactation (17 June-16 August 2006) and post-lactation period (17 August-27 September 2006).

Measurements of metabolic rate

We determined MR of roosting groups of bats by continuously measuring the rate of oxygen consumption using portable gas analyzers with chemo-electric sensors (Bieler and Lang, Achern, Germany; accuracy $<0.02$ vol.\%; Schmid et al. 2000, Dausmann et al. 2009). Oxygen sensors were calibrated directly before the field season in the laboratory using calibration gas made by a gas-mixing pump (Wösthoff, Bochum, Germany, type G27).

Bat boxes served as metabolic chambers (volume approximately $2,500 \mathrm{~cm}^{3}$, dimensions inside: height, $22 \mathrm{~cm}$; diameter, $12 \mathrm{~cm}$; thickness of wall, $2 \mathrm{~cm}$ ), with the entrance as air inlet. The entrance of each bat box is at the bottom of the box (opening size, $6.5 \times 3 \mathrm{~cm}$ ). A small hole (approximately $8 \mathrm{~mm}$ ) was drilled into the roof of each box, and a tube adaptor was attached in spring before bats arrived. We were able to connect the analyzer system to the bat boxes using a gastight tube without any disturbances of the bats, as later confirmed by MR measurements. The area of contact between the lid of each bat box and the walls of each bat box were sealed with plasticine to restrict diffusion of air when the gas analyzer was operating. Air was pumped through the bat boxes at a flow rate of $80 \mathrm{l} / \mathrm{h}$. The air was filtered from particles and dried with silica gel after leaving bat boxes. This was done before the air samples entered the gas analyzer. Oxygen content of the sample air from inside the boxes was measured once per minute. To control for any drift of the oxygen sensor, we sampled reference air (baseline) in the ambient environment just outside of the bat boxes once per minute. We calculated MR (millilitres $\mathrm{O}_{2}$ per hour) according to Withers (2001), assuming a constant RQ of 0.85 and correcting the values for ambient pressure and $T_{\mathrm{a}}$.

We took 87 measurements of oxygen consumption of different roosting groups almost each day over 109 days between 15 May 2006 and 31 August 2006. The energy expenditure for each roosting group in each bat box was calculated as daily resting energy expenditure (DREE). This is a minimum estimate of energy expenditure because it does not include additional costs of foraging. We calculated DREE in millilitres $\mathrm{O}_{2}$ per hour from the average MR from 1200 to 1900 hours. This time frame was chosen because 
comparable data sets were available for this period and this is one of the most consistent resting phases of Bechstein's bats (this study) as well as of other vespertilionid bat species (Burnett and August 1981; Winchell and Kunz 1996). This time frame nevertheless also comprised phases when the bats were active, engaging in grooming and social interactions. To present results for energy expenditure (kilojoules per day) of each roosting group, we transferred DREE into units of power. At the RQ of 0.85 (combustion of $50 \%$ fat and $50 \%$ carbohydrates; Dausmann et al. 2009), the caloric equivalent of oxygen consumption is $20.37 \mathrm{~kJ} / 1 \mathrm{O}_{2}$ (Heldmaier and Neuweiler 2004). During the post-lactation period, we did not calculate DREE because bats entered torpor every day when we measured oxygen consumption. To compare energy expenditure between different group sizes, we calculated MR per animal in a roosting group. Thus, MR data (MR/DREE) are presented as an hourly mean $\pm \mathrm{SD}$ in millilitres $\mathrm{O}_{2}$ per hour per animal or kilojoules per day per animal, respectively, unless otherwise stated. All other data are presented as means $\pm \mathrm{SD}$.

To estimate how not pit-tagged juveniles may have influenced our calculations of energy expenditure of a roosting group, we additionally calculated MR per animal accounting for the increasing share of juveniles on total group. During the pre-lactation period and the first 4 days of the lactation period, when the juveniles are naked and presumably still poikilotherm (Weigold 1973; Hollis and Barclay 2008), total group size in a roost for calculations of MR refers to adult females only. Later in the season, group size included one juvenile for each mother (e.g. in a box with ten lactating females and four non-lactating ones, we assumed a total group size of 24 bats). To calculate MR per animal, we assumed a linear increase in MR of juveniles as juvenile growth generally is linear during this period (until the onset of flight; Kunz 1987). Following Kunz (1987), we assumed juvenile MR to be $10 \%$ of the average adult MR on a given day in a given roosting group on days 5 and 6 post-partum. On days 7 and 8 after birth, we assumed juvenile MR to be $20 \%$ of the average adult MR on a given day in a given roosting group. We assumed juvenile MR to reach adult level starting on day 23 after birth. This corresponds to the late pre-flight period when other juvenile Myotis species approach both the range of adult masses (Kunz 1987) and the thermoregulatory capability of adults (Weigold 1973; Hollis and Barclay 2008).

\section{Torpor}

Torpid and non-torpid states were differentiated based on MR of the whole roosting group. Following Hudson and Scott (1979), we defined bats as being torpid when MR declined by at least $25 \%$ in relation to the MR value $60 \mathrm{~min}$ before at stable $T_{\mathrm{a}}$ and stayed in this range for at least
$60 \mathrm{~min}$. A time frame of $30 \mathrm{~min}$ after post-feeding return was not considered because then MR declines, but reflects the change from MR during flight to resting MR. When MR increased, the animals were assumed to have aroused to become normothermic (Heldmaier and Ruf 1992; Geiser and Ruf 1995; Wang 2000). To standardise analysis of MR during torpor despite differences in torpor bout lengths, mean MR from each particular torpor bout was calculated for two 30-min time intervals. The first mean was taken from values from as soon as MR reached minimal value for the first time during the experimental trial; the second mean was taken from values starting $30 \mathrm{~min}$ before MR increased again from the minimal value. The duration of a torpor bout was defined as the time during which oxygen consumption had reached a minimal value until it began to increase. This is analogous to the initial decline of MR in the definition of torpor. As far as could be detected with a thermographic camera (FLIR ThermaCAM ${ }^{\mathrm{TM}}$ E2, Flir Systems Inc., Portland, USA), which we held at the bat box entrance, bats inside a bat box were either all normothermic or all torpid. Thus, we assume that all bats in a bat box on a given day had the same thermoregulatory state (normothermic/torpid).

Because both colonies frequently split into several groups but maximal two gas analyzers were available, we could not take measurements of MR of all roosting groups simultaneously. Therefore, we inferred thermoregulatory state based on the difference between $T_{\text {out }}$ and $T_{\text {roost }}$ when measurements of MR of roosting groups were not available (61.2\% of 224 located roosting groups). Bats were assumed to have stayed normothermic when $T_{\text {roost }}$ remained stable at a constant elevated temperature after bats arrived in the bat boxes (see Fig. 1a) despite changes in $T_{\mathrm{a}}$. Bats were assumed to be torpid when $T_{\text {roost }}$ fell below $20^{\circ} \mathrm{C}$ and resembled the outside temperature $T_{\text {out }}\left( \pm 2.5^{\circ} \mathrm{C}\right)$. In 45 out of 269 roosting groups, the thermoregulatory state could not be determined because bats used a bat box for the first time and no iButton had yet been attached inside the bat box.

\section{Data analysis}

We considered the daily occupation of roosts and every day of our MR measurements to be statistically independent because of the frequent roost switching (Kerth and König 1999). Because mean daily group size did not differ significantly between the two colonies ( $U$ test, only adults: $Z=-0.192, N=$ 269 roosting groups, $P=0.848$; $U$ test, with juveniles: $Z=$ $-0.440, N=269$ roosting groups, $P=0.660$ ), we pooled the data from the two colonies.

To calculate mean group size on a given day, data from days when we could not find more than $20 \%$ of colony members were omitted from the analysis because small groups are easier to overlook in the boxes and we wanted to avoid a bias towards larger group size. 
Fig. 1 a Group metabolic rate of a group of eight normothermic adult Bechstein's bats (Myotis bechsteinii; three lactating and five non-reproductive) in a bat box during the lactation period when juveniles were volant. A nightly visit of a single bat in the box is indicated. b Group metabolic rate of $M$. bechsteinii during torpor and normothermia roosting in a group of 11 adult females (six post-lactating and five non-reproductive) during the post-lactation period. The bats did not return to the same box after they left at 2100 hours. Vertical line indicates midnight; black horizontal bars at the top show the dark phase. Additionally, ambient temperature (solid line) and roost temperature (dashed line) are shown. Figure 1 is shown as an example for the type of data we collected
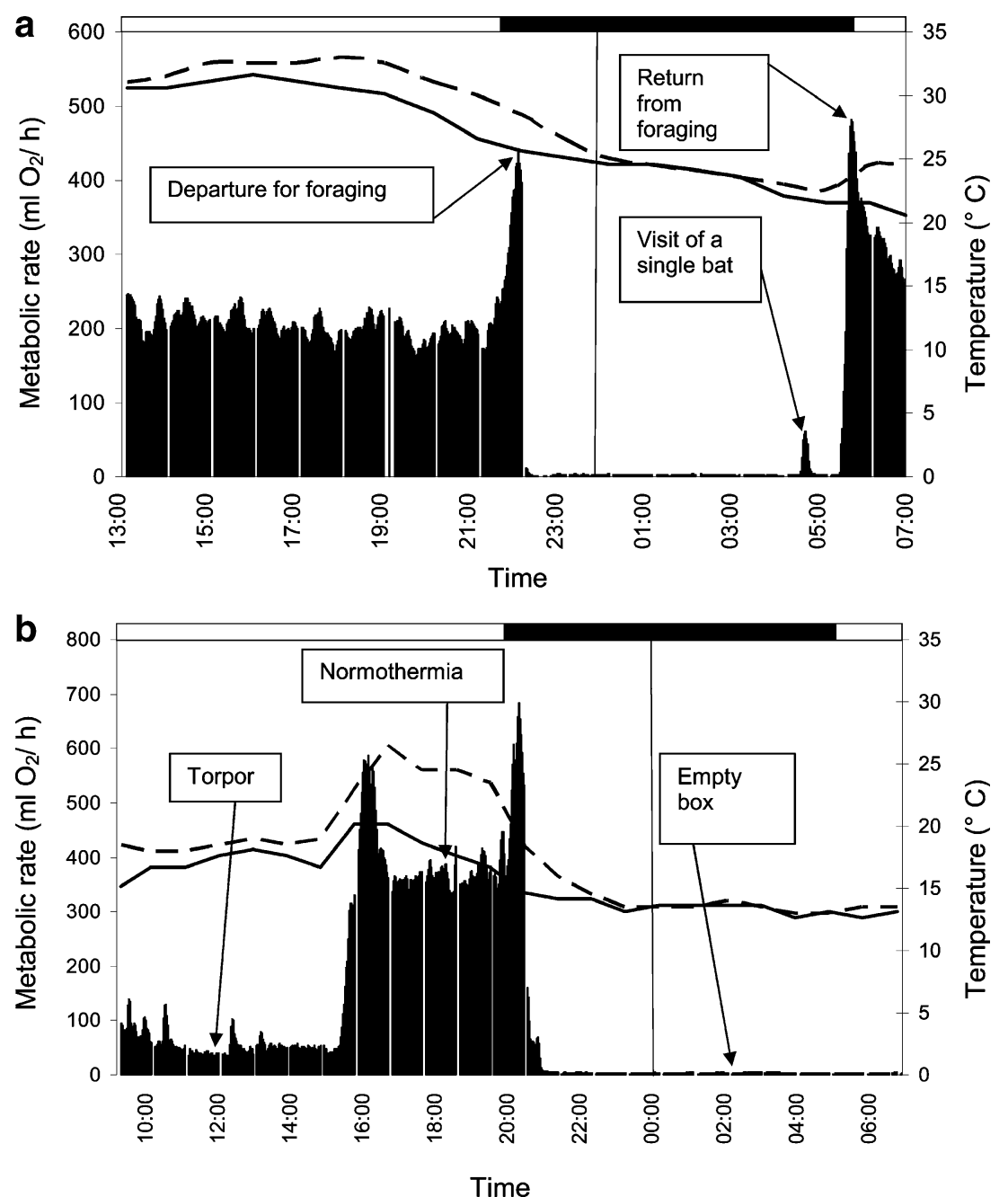

Statistical analyses were completed using SPSS version 15.0 for Windows. To analyse the effect of group size, $T_{\text {roost }}, T_{\text {out }}$ and $T_{\mathrm{a}}$ on DREE, a general linear model (GLM) was performed using R (R Development Core Team 2009). Backward stepwise selection was applied to exclude nonsignificant independent variables from the model. The influence of $T_{\mathrm{a}}$ and group size on $T_{\text {roost }}$ was analysed in a second GLM. We employed an alpha value of 0.05 for twotailed tests. Depending on whether data were normally distributed, we employed parametric or nonparametric tests.

\section{Results}

Colony size, group size, group composition, body mass

The colonies consisted of 13 adult females in the "Blutsee" colony and 35 adult females in the "Guttenberg 2" colony. Mean body mass of adult females was $10.3 \pm 0.9 \mathrm{~g}$ (pregnant, $10.7 \pm 0.6 \mathrm{~g}(N=29)$; non-reproductive, $9.6 \pm 1.1 \mathrm{~g}(N=19))$ in May 2006 and $9.9 \pm 0.4 \mathrm{~g}$ (lactating, $10.0 \pm 0.4 \mathrm{~g}(N=29)$; non-reproductive, $9.7 \pm 0.4 \mathrm{~g}(N=19))$ in August 2006. Mean mass of juveniles was $8.7 \pm 0.5 \mathrm{~g}$ (range, 7.5-9.5 g) in August. Most (96\%) roosting groups consisted of reproductive and non-reproductive females. Mean daily group size was $10.3 \pm 3.8$ adult females $(N=103$; with juveniles, $15.4 \pm$ $6.5)$ in the "Blutsee" colony and $11.0 \pm 6.0$ adult females $(N=$ 166; with juveniles, 15.8 \pm 9.1 ) in the "Guttenberg 2" colony.

Temperature regime

Bats returned to the boxes early in the morning, about the time during which the minimal nightly temperatures occurred. Minimum $T_{\mathrm{a}}\left(T_{\mathrm{a}} \mathrm{min}\right)$ was significantly correlated with maximal $T_{\mathrm{a}}\left(T_{\mathrm{a}} \max\right.$; Pearson correlation: $r=0.657$, $N=159$ days, $P<0.001$ ), i.e. temperatures did not rise as high on days with cold nights. Thus, we used $T_{\mathrm{a}}$ min as an indicator of the weather of any given day, which ranged from $-1.6^{\circ} \mathrm{C}$ to $18.5^{\circ} \mathrm{C}$ (mean, $10.4 \pm 4.1^{\circ} \mathrm{C} ; N=159$ days) and $T_{\mathrm{a}}$ max from $7.7^{\circ} \mathrm{C}$ to $34.6^{\circ} \mathrm{C}$ (mean, $22.7 \pm 5.3^{\circ} \mathrm{C} ; N=$ 159 days). $T_{\mathrm{a}}$ min and $T_{\mathrm{a}}$ max differed significantly between the reproductive periods (ANOVA $\left(T_{\mathrm{a}} \mathrm{min}\right): F_{2,156}=85.64$, 
$P<0.001$; ANOVA ( $\left.\left.T_{\mathrm{a}} \max \right): F_{2,156}=37.11, P<0.001\right) . T_{\mathrm{a}}$ $\min$ and $T_{\mathrm{a}}$ max during the pre-lactation period both were significantly cooler than during the post-lactation and lactation periods, the latter being the warmest (Table 1).

Metabolic rate during normothermia

On 71 of the 87 days when MR was measured, groups remained normothermic, whereas on 16 days, they were torpid. Bats returned from foraging early in the morning, stayed within the bat box during the day $(17.5 \pm 1.6 \mathrm{~h}, N=$ 41 days) and departed at dusk. Our gas analyzer worked efficiently and was able to identify even short visits by individuals during the night (Fig. 1a), and this was confirmed by the automatic transponder reader.

During normothermia, average DREE for adult females for the entire field season was $30.9 \pm 7.0 \mathrm{ml} \mathrm{O}_{2}$ per hour per animal ( $N=71$ days). Mean DREE corresponds to $15.1 \pm$ $3.4 \mathrm{~kJ} /$ day $(N=71$ days). With juveniles (counted as measured individuals), mean DREE for the entire field season was $25.3 \pm 8.7 \mathrm{ml} \mathrm{O}_{2}$ per hour per animal, corresponding to $12.4 \pm 4.3 \mathrm{~kJ} /$ day. Mean DREE is given separately for the three reproductive periods in Table 1 . Mean MR for adult females shortly before and after the nightly flights (averaged over $10 \mathrm{~min}$ ) was double that of the mean DREE during the afternoon, reflective of high energy expenditure during foraging flights and reaching $61.3 \pm 14.3 \mathrm{ml} \mathrm{O}_{2}$ per hour per animal ( $N=71$ days, Fig. $\left.1 \mathrm{a}\right)$. The lowest hourly mean value recorded during the day in normothermic groups before parturition was $10.9 \mathrm{ml} \mathrm{O}$ per hour per animal on a warm day $\left(T_{\text {roost }}=36^{\circ} \mathrm{C}\right)$ with generally low MR. During all data recording trials, reproductive females roosted together with non-reproductive females, so comparing MR between the two reproductive states was not possible.

Metabolic rate during torpor

Torpor use was most common during the post-lactation period, occurring on $71.4 \%$ of the groups $(N=63)$ compared to $22.2 \%$ ( $N=27$ groups) and $21.6 \% \quad(N=134$ groups) during the pre-lactation and lactation periods, respectively.
Mean torpid MR at a mean $T_{\mathrm{a}}$ of $13.8 \pm 1.7^{\circ} \mathrm{C}$ is shown in Table 1. On average, bats reduced MR during torpor by $85.5 \%$ compared to mean DREE. The lowest hourly value recorded during torpor was $0.77 \mathrm{ml} \mathrm{O}_{2}$ per hour (with juveniles, $0.44 \mathrm{ml} \mathrm{O}_{2}$ per hour), and the maximal value was $8.6 \mathrm{ml} \mathrm{O}_{2}$ per hour (with juveniles, $4.79 \mathrm{ml} \mathrm{O}_{2}$ per hour).

Bats entered torpor in the early mornings (at $0800 \pm$ 3 hours), remained torpid throughout the day and became active in the afternoon (Fig. 1b) or evening (between 1615 and 1855 hours). Mean length of a torpor bout was $10.3 \pm$ $9.5 \mathrm{~h}$ ( $N=15$ torpor bouts), ranging from 1.8 to $44.0 \mathrm{~h}$. Bechstein's bats remained torpid significantly longer on colder days (Pearson correlation: $r=-0.763, N=15$ torpor bouts, $P=0.001$; i.e. when $T_{\mathrm{a}}$ was $15.7^{\circ} \mathrm{C}$, torpor bout length was $1.75 \mathrm{~h}$, and when $T_{\mathrm{a}}$ was $8.3^{\circ} \mathrm{C}$, torpor bout length was $29 \mathrm{~h}$ ), and therefore, energy savings increased with decreasing $T_{\mathrm{a}}$. On days when bats entered torpor, $T_{\mathrm{a}}$ was significantly lower, with an average $T_{\mathrm{a}}$ min of $10.1 \pm$ $2.1^{\circ} \mathrm{C}(t$ test: $t=8.5, d f=220, P<0.001)$. For further analysis of the relationship between $T_{\mathrm{a}}$, group size and MR, we only used the data on DREE of normothermic animals, unless explicitly stated otherwise.

Relationship between group size, temperature and metabolic rate

$T_{\mathrm{a}}$ min influenced group size only during the post-lactation period (Spearman rank correlation; Table 2). During this time, which is also the period of frequent torpor bouts, group size decreased as $T_{\mathrm{a}}$ decreased (Table 2). Also, group size was significantly smaller for bats that used torpor than for those that did not ( $U$ test: $Z=-7.204, N=224$ roosting groups, $P<0.001$; with juveniles: $U$ test: $Z=-5.817, N=224$ roosting groups, $P<0.001$; Table 2). Therefore, bats generally formed smaller groups on days when they used torpor. However, depending on the reproductive period, bats did not always roost in small groups and enter torpor.

Our GLM analysis revealed a significant effect of maximal $T_{\text {out }}$ and the number of normothermic bats inside a roost on maximal $T_{\text {roost }}\left(F_{2,73}=48.78, P<0.001, R^{2}=\right.$ 0.572; with juveniles: $F_{2,73}=51.54, P<0.001, R^{2}=0.585$ ). A greater number of bats (all normothermic) inside a roost

Table 1 Mean minimal ambient temperature $\left(T_{\mathrm{a}} \min \right)$ and DREE of Bechstein's bats (Myotis bechsteinii) in roosting groups given separately for the three reproductive periods (mean $\pm \mathrm{SD} ; N$ number of days $\left(T_{\mathrm{a}} \min / T_{\mathrm{a}} \max \right)$ and number of measurements (DREE))

\begin{tabular}{llll}
\hline Period & $T_{\mathrm{a}} \min / T_{\mathrm{a}} \max \left({ }^{\circ} \mathrm{C}\right)$ & \multicolumn{2}{l}{$\mathrm{DREE}\left(\mathrm{ml} \mathrm{O} \mathrm{O}_{2}\right.$ per hour)/Energy expenditure (kJ/day) } \\
\cline { 3 - 4 } & & Only adult females & With juveniles \\
\hline Pre-lactation & $6.8 \pm 3.4 / 19.1 \pm 4.8(N=56)$ & $33.2 \pm 10.0 / 16.2 \pm 4.9(N=18)$ & Not born yet \\
Lactation & $13.4 \pm 2.8 / 26.1 \pm 4.8(N=61)$ & $30.0 \pm 5.4 / 14.7 \pm 2.6(N=53)$ & $22.6 \pm 6.4 / 11.0 \pm 3.1(N=53)$ \\
Post-lactation & $10.9 \pm 2.4 / 22.2 \pm 3.2(N=42)$ & $4.5 \pm 1.2 / 2.2 \pm 0.6($ torpor, $N=16)$ & $2.5 \pm 0.7 / 1.2 \pm 0.3($ torpor, $N=16)$ \\
\hline
\end{tabular}


Table 2 Relationship between group size and minimal ambient temperature $\left(T_{\mathrm{a}}\right)$

Mean group sizes for

Bechstein's bats (Myotis bechsteinii) that entered torpor and that remained normothermic are shown. Results for only adult females are given in comparison to results considering the presence of juveniles ( $N$ number of roosting groups). During the pre-lactation period, offspring was not born yet, and therefore, only one value is given

\begin{tabular}{lll}
\hline Spearman rank correlation & Only adult females & With juveniles \\
\hline Pre-lactation period & $r_{\mathrm{s}}=0.053, N=61, P=0.688$ & \\
Lactation period & $r_{\mathrm{s}}=0.092, N=134, P=0.290$ & $r_{\mathrm{s}}=0.088, N=134, P=0.313$ \\
Post-lactation period & $r_{\mathrm{s}}=0.257, N=74, P=0.027$ & $r_{\mathrm{s}}=0.248, N=74, P=0.033$ \\
Mean group size-torpor & Mean: $7.6 \pm 5.9, N=80$ & Mean: $12.1 \pm 8.3, N=80$ \\
Pre-lactation period & $5.3 \pm 4.4(N=6)$ & \\
Lactation period & $9.4 \pm 5.5(N=29)$ & $15.2 \pm 9.0(N=29)$ \\
Post-lactation period & $6.7 \pm 4.4(N=45)$ & $10.9 \pm 7.5(N=45)$ \\
Mean group size-normothermia & $12.3 \pm 4.9, N=144$ & $18.3 \pm 7.7, N=144$ \\
Pre-lactation period & $12.3 \pm 1.2(N=21)$ & \\
Lactation period & $11.9 \pm 4.5(N=105)$ & $19.1 \pm 7.9(N=105)$ \\
Post-lactation period & $13.1 \pm 4.9(N=18)$ & $20.9 \pm 7.6(N=18)$ \\
\hline
\end{tabular}

( $t=0.115, P<0.001$; with juveniles: $t=1.71, P=0.091$ ) and higher outside $T_{\text {out }}(t=0.08, P<0.001$; with juveniles: $t=$ $8.58, P<0.001)$ both resulted in a higher $T_{\text {roost }}$. The mean temperature difference, $T_{\text {roost }}-T_{\text {out }}$, was $0.5 \pm 0.7^{\circ} \mathrm{C}$ in unoccupied roosts $(N=58)$ and $4.6 \pm 4.1^{\circ} \mathrm{C}$ in occupied roosts $\left(N=88\right.$; pre-lactation, $5.1 \pm 2.9^{\circ} \mathrm{C} ; N=21$; lactation, $3.9 \pm 3.4^{\circ} \mathrm{C}, N=55$; post-lactation, $\left.4.8 \pm 3.1^{\circ} \mathrm{C}, N=12\right)$. Mean $T_{\text {roost }}$ (1200 to 1900 hours) was $23.0 \pm 5.2^{\circ} \mathrm{C}$ during prelactation, $28.9 \pm 4.3^{\circ} \mathrm{C}$ during lactation and $23.2 \pm 4.9^{\circ} \mathrm{C}$ during the post-lactation period. Therefore, increase in $T_{\text {roost }}$ (likely due to social thermoregulation) in normothermic bats was highest during the pre-lactation period when many bats were pregnant, although $T_{\text {roost }}$ was lowest during this period due to low $T_{\text {out }}$.

For normothermic bats, the resulting GLM model for mean DREE was highly significant (adults: $F_{5,64}=15.75$, $P<0.001, R^{2}=0.552$; with juveniles: $F_{5,64}=28.31, P<$ $\left.0.001, R^{2}=0.689\right)$. $T_{\text {roost }}$ had a significant effect on mean DREE (adults: $t=-2.41, P=0.019$ ), but not with juveniles $(t=-0.72, P=0.4720) . T_{\text {out }}$ also affected mean DREE (adults: $t=-4.88, P<0.001$; with juveniles: $t=-5.54, P<$ 0.001 ), group size (adults: $t=-2.18, P=0.033$; with juveniles: $t=-4.51, P<0.001$ ), the reproductive period (adults: $t=$ $-3.31, P=0.0015$; with juveniles: $t=-3.07, P=0.0031)$ and the interaction between the reproductive period and maximal $T_{\text {out }}$ (adults: $t=4.10, P<0.001$; with juveniles: $t=3.26, P=$ $0.0018)$. In contrast, minimal $T_{\mathrm{a}}$ outside the bat box had no significant influence on mean DREE in adults and was excluded by backward stepwise elimination $\left(F_{1,40}=0.0012\right.$, $P=0.972)$. With increasing $T_{\text {out }}$ and $T_{\text {roost }}$, normothermic adults expended less energy (Fig. 2a, b, respectively). This relationship was more pronounced during the pre-lactation period ( $y=-1.5214 x+74.7705$ for residuals) than later in the season ( $y=-0.3412 x+44.4031$ for residuals). Moreover, with increasing group size, adults significantly reduced DREE (Fig. 2c). During their diurnal roosting time, the bats expended significantly less energy (adults, 14\% of DREE; with juveniles, $7 \%$ of DREE) when roosting in larger groups (more than ten animals: adults, $29.6 \pm 6.2 \mathrm{ml} \mathrm{O}_{2}$ per hour; with juveniles, $23.6 \pm 7.8 \mathrm{ml} \mathrm{O}_{2}$ per hour) compared to roosting in smaller groups (less than ten animals: adults, $34.3 \pm$ $7.6 \mathrm{ml} \mathrm{O}_{2}$ per hour; with juveniles, $28.4 \pm 9.5 \mathrm{ml} \mathrm{O}_{2}$ per hour) at the same $T_{\mathrm{a}}$ ( $t$ test: $t=2.825, d f=71, P=0.006$ ). Energy expenditures of adult females only during the pre-lactation period and during lactation (Table 1) were not different $(t$ test: $t=1.26, d f=20.5, P=0.221)$. However, when considering that juveniles also expend energy, the bats expended significantly more energy during the pre-lactation (no juveniles were born yet) than during the lactation period (Table $1 ; t$ test: $t=2.33, d f=69, P=0.023$ ).

\section{Discussion}

Metabolic rates of Bechstein's bats during normothermia are influenced by group size and roost temperature

Our study of free-ranging Bechstein's bats confirmed the results from previous laboratory studies showing that MR in normothermic mammals is strongly influenced by $T_{\mathrm{a}}$ (e.g. Hock 1951; McNab 1982; Hosken and Withers 1997). We found that MR decreased with increasing $T_{\text {roost }}$, which is similar to patterns recorded for other mammals that use shelters of restricted space (e.g. Arnold 1988), such as tree cavities or nest boxes, where $T_{\text {roost }}$ increases with increasing group size. Indeed, when calculating energy expenditure over the entire field season, normothermic adults maintained their DREE largely constant, despite changes in daily minimal $T_{\mathrm{a}}$ (the general $T_{\mathrm{a}}$ in the forest), when roosting in groups of varying sizes, which influenced $T_{\text {roost }}$. This might have been achieved by varying levels of activity (i.e. grooming, alertness, resting; Winchell and Kunz 1996) during normothermia or simply by the presence of more animals (all normothermic).

Our data demonstrate the efficiency of social thermoregulation in normothermic bats. Females roosting in larger 

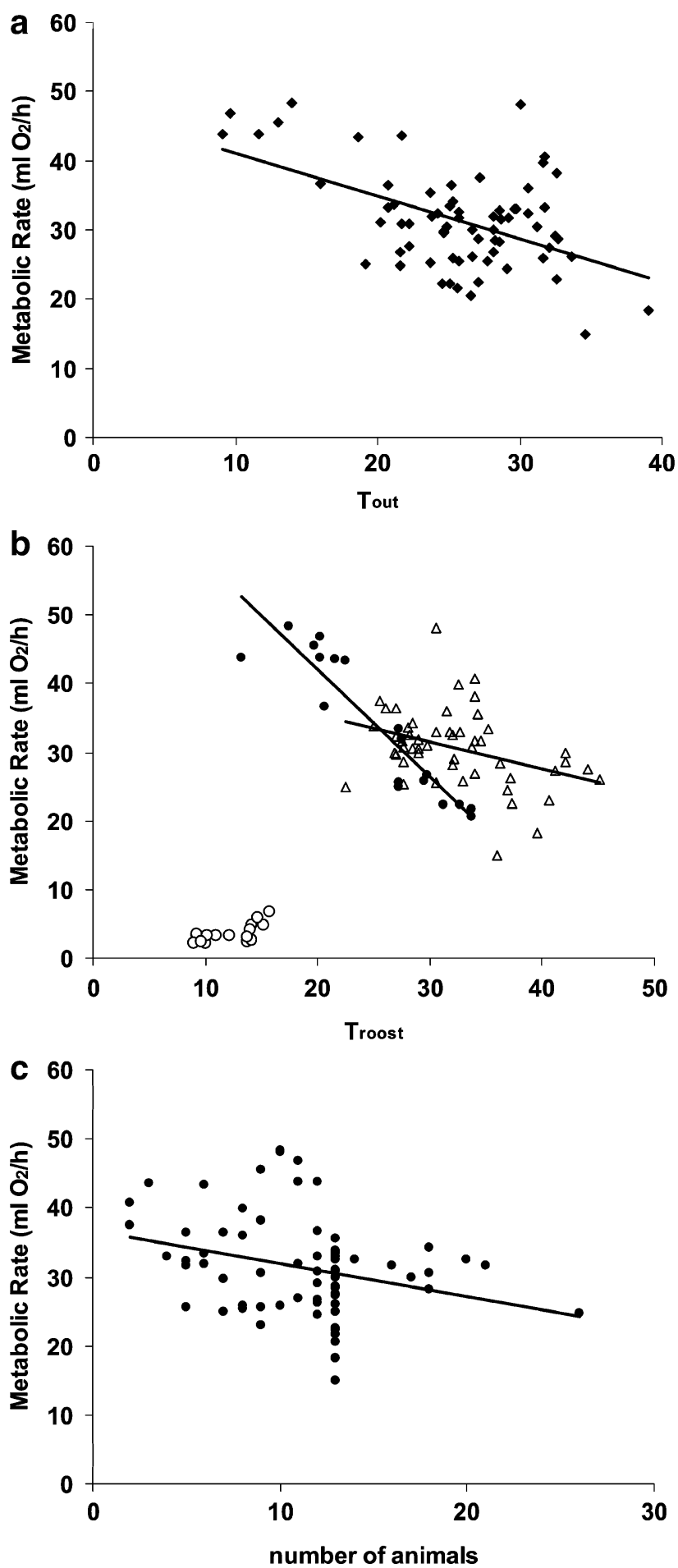

Fig. 2 Regression analysis of the dependence between mean DREE in adult Bechstein's bats ( $M$. bechsteinii) and the factors daily maximal outside temperature $\left(T_{\text {out }}\right)(\mathbf{a})$, daily maximal roost temperature $\left(T_{\text {roost }}\right)$ (b; open triangles lactation period; filled circles pre-lactation period) and group size (c). In $\mathbf{b}$, mean daily torpid metabolic rate with minimal daily $T_{\text {roost }}$ is additionally shown (open circles, $N=15$ torpor bouts) groups (more than ten bats) saved approximately 15\% (with juveniles: approximately $7 \%$ ) of the energy used by females roosting in smaller groups (ten or less bats) at the same $T_{\mathrm{a}}$. Nevertheless, maximal $T_{\text {out }}$, reproductive period and the interaction between these had a greater influence on energy expenditure than group size and $T_{\text {roost }}$ alone. On warm days, normothermic bats were able to significantly reduce their energy expenditure. On colder days, the affect of social thermoregulation was higher. Then, the difference between $T_{\text {roost }}$ and $T_{\text {out }}$ was highest, but $T_{\text {roost }}$ was nevertheless lower. Thus, bats cannot completely compensate for low $T_{\mathrm{a}}$ solely by social thermoregulation. Moreover, some laboratory studies suggest that benefits of clustering diminish with increasing number of individuals (Canals et al. 1989; Perret 1998; Boyles et al. 2008). Bechstein's bats appear to achieve energy balance by selecting warmer roosts on colder days (Kerth et al. 2001), thereby avoiding cooler temperatures that would imply higher thermoregulatory costs.

Considering the presence of juveniles when calculating MR did not change our results qualitatively, although the relative importance of factors on MR was slightly different. Bats saved the most energy at warmer $T_{\text {out }}$ and group size was less important when considering juveniles. Regardless, bats profited energetically from clustering. $T_{\text {roost }}$ had no significant affect on mean DREE during the lactation period, presumably because the heat generated through clustering is most effective during colder periods. Including juveniles in analysis, lactation was energetically less expensive than the colder pre-lactation period when females expended approximately $20 \%$ more energy. Thus, as expected, both low $T_{\mathrm{a}}$ (especially during the pre-lactation period) and smaller groups increased MR in normothermic bats. The lowest hourly MR value occurred on a warm day before pups were born, $33.7 \%$ lower than the predicted basal metabolic rate (BMR) for a 10 -g bat $\left(16.5 \mathrm{ml} \mathrm{O}_{2}\right.$ per hour according to Eq. 1 by Speakman and Thomas 2003). But our recorded value is in accordance with results of BMR measurements from other vespertilionid bats with a similar body mass, ranging from $10.0 \mathrm{ml} \mathrm{O}_{2}$ per hour for a 11.2-g Histiotus velatus ( $T_{\text {roost }}$ unknown) to $18.7 \mathrm{ml} \mathrm{O}_{2}$ per hour per animal for a 7.7-g Myotis lucifugus with $T_{\text {roost }}=$ $24^{\circ} \mathrm{C}$ (reviewed in Speakman and Thomas 2003).

The propensity to show torpor was not exclusively dependent on ambient conditions, especially during the prelactation and lactation periods, although $T_{\mathrm{a}}$ was usually low when bats entered torpor. Whenever $T_{\mathrm{a}}$ fell below $11^{\circ} \mathrm{C}$ during the post-lactation period, bats used torpor. However, the bats remained normothermic during $76 \%$ of the time during the pre-lactation period and in $37 \%$ of the time during the lactation period when $T_{\mathrm{a}}$ fell below $11^{\circ} \mathrm{C}$. Considering $T_{\mathrm{a}}$ is generally colder during the pre-lactation period, which would increase thermoregulatory demands 
when remaining normothermic, it is even more noteworthy that female Bechstein's bats only employed torpor in about a quarter of the days during this time and during lactation. It is likely that female Bechstein's bats cannot energetically afford to enter torpor more frequently whilst pregnant or lactating without risking the timely development of the young and milk production (Geiser 1996). We suggest that bats compensated for low $T_{\mathrm{a}}$ whilst remaining normothermic by roosting in larger groups during the pre-lactation and lactation periods and entering torpor as often as they could afford to do so.

Generally, larger group sizes resulted in higher $T_{\text {roost }}$ and thus substantial daily energy savings in normothermic bats. Mutual warming as a result of social thermoregulation is limited, and clustering is less effective to save energy than entering torpor because MR in normothermic clusters cannot fall below basal levels in contrast to during torpor (Heldmaier and Ruf 1992; Geiser 2004). Other bat species including E. fuscus (Lausen and Barclay 2003) and Myotis daubentonii (Dietz and Kalko 2006) also used torpor more frequently after weaning than during lactation and prelactation. Pregnant E. fuscus used torpor less frequently, but with more time in deep torpor than lactating bats (Lausen and Barclay 2003). These differences are likely more related to reproductive condition rather than to physiological capability (Turbill and Geiser 2006).

Torpor is more energetically beneficial in small groups

During the post-lactation period, Bechstein's bats formed significantly smaller groups when $T_{\mathrm{a}}$ was low. Although the post-lactation period was not the coldest time of the breeding season, all bats employed torpor more than twice as often during this time than in other periods. Also, mean group size during torpor was only half of that during normothermia (with juveniles, it was 30\% smaller). We suggest that Bechstein's bats formed smaller groups when employing torpor to increase the length of the torpor episode and thus the period of energy savings. Roosting in smaller groups during torpor reduces the risk of disturbance by conspecifics arousing earlier for foraging or other activities and also allows for avoidance of passive warming caused by aroused normothermic roost mates, which would decrease the energetic benefits of being torpid due to shorter torpor bouts (KH Dausmann, unpublished data). Small groups also allow faster cooling which prolongs torpor bouts and therefore greater energetic savings. Temperate bats have to accumulate sufficient body fat over a relatively short period at the end of the summer prior to hibernation. Entering torpor reduces metabolic and thermoregulatory costs. Thus, it might be important for Bechstein's bats to minimise energy expenditure by using torpor frequently during the post-lactation period to accumulate fat stores for hibernation (Ewing et al. 1970; Speakman and Rowland 1999).

As expected, $T_{\mathrm{a}}$ was significantly lower on days when bats entered torpor, and torpor led to a substantial reduction of MR (on average by $86 \%$ ) in adult Bechstein's bats compared to DREE when they remained normothermic. Longer torpor bouts yielded energy savings of up to $94 \%$ per day. Our estimates are conservative because we did not consider increased thermoregulatory costs associated with decreasing $T_{\mathrm{a}}$ (when torpor was most often exhibited), nor the additional costs of activity that would have occurred if the bats had remained normothermic. Our measurements of mean and minimal MR during torpor coincided with values reported in studies carried out at comparable $T_{\mathrm{a}}$ in other vespertilionid bat species of similar size under laboratory conditions (Geiser 1988; Speakman and Thomas 2003).

Thermoregulatory strategy depends on reproductive status and ambient conditions

The use of torpor by reproductive female bats differs between and within species and might be influenced by body size, climate, foraging ecology, colony size and roost type (Solick and Barclay 2006; Willis 2006). Data recorded for Bechstein's bats suggest that even within the same colony, the physiological strategy for successful reproduction and/or survival may differ between years and the reproductive periods depending on the weather (Kerth et al. 2001, this study). During an extremely cold spring in 1996, female Bechstein's bats chose cool roosts during pregnancy (probably to enter torpor), and the birth rate of that year was much lower (Kerth et al. 2001). However, later in that same year when temperatures had increased, females preferred warmer roosts, which would have facilitated normothermia. Combined, our study and Kerth et al. (2001) suggest that female Bechstein's bats, similar to female M. daubentonii (Dietz and Kalko 2006), employ torpor less during pregnancy and lactation, likely to maximise offspring development, provided that weather conditions are not too adverse to risk the survival of potential mothers. We found that five out of 269 roosting groups consisted of a mixture of reproductive and nonreproductive females, even though the two groups have different physiological demands (Kerth and König 1999; Kerth et al. 2001). Particularly during cold weather, nonreproductive females would be expected to profit from entering torpor (Studier 1981; Kerth et al. 2001; Solick and Barclay 2006) instead of remaining normothermic and roosting together with reproductive females, which could be interpreted as cooperative warming (Kerth 2008).

We were able to demonstrate on wild Bechstein's bats during different reproductive periods the significance of behavioural and physiological flexibility for optimal thermoregulatory behaviour in small endotherms and the importance 
of field studies where the animals can use their behavioural and physiological repertoire, which is often not possible under the generally more controlled regimes in laboratory studies.

Acknowledgements The authors thank Insa Wagner, Sabine Muff and Pascal Schaer for their help in the field. Thomas Broquet, Michel Genoud, Barbara König, William J. Foley and three anonymous referees provided helpful comments on earlier drafts of this paper. Handling of Bechstein's bats was carried out under license from the nature conservancy department of Lower Franconia (Obere Naturschutzbehörde der Regierung von Unterfranken). We gratefully acknowledge their support and that of the local department of forestry. We also thank the 'Landesamt für Wald-und Forstwirtschaft (LWF)' for providing the data from their meteorological station. Iris Pretzlaff was supported by the 'Heinrich-Böll-Stiftung', Gerald Kerth by the German Science Foundation (DFG, KE 746, 2-1)

Open Access This article is distributed under the terms of the Creative Commons Attribution Noncommercial License which permits any noncommercial use, distribution, and reproduction in any medium, provided the original author(s) and source are credited.

\section{References}

Arnold W (1988) Social thermoregulation during hibernation in alpine marmots (Marmota marmota). J Comp Physiol B 158:151-156

Boyles JG, Storm JJ, Brack V Jr (2008) Thermal benefits of clustering during hibernation: a field test of competing hypotheses on Myotis sodalis. Funct Ecol 22:632-636

Burnett CD, August PV (1981) Time and energy budgets for day roosting in a maternity colony of Myotis lucifugus. J Mammal 62:758-766

Canals M, Rosenmann M, Bozinovic F (1989) Energetics and geometry of huddling in small mammals. J Theor Biol 141:181-189

Chruszcz B, Barclay RMR (2002) Thermoregulatory ecology of a solitary bat, Myotis evotis, roosting in rock crevices. Funct Ecol $16: 18-26$

Dausmann KH, Glos J, Heldmaier G (2009) Energetics of tropical hibernation. J Comp Physiol B 179:345-357

Davis WH (1970) Hibernation: ecology and physiological ecology. In: Wimsatt WA (ed) Biology of bats, vol 1. Academic, New York, pp 265-300

Dietz M, Kalko EKV (2006) Seasonal changes in daily torpor patterns of free-ranging female and male Daubenton's bats (Myotis daubentonii). J Comp Physiol B 176:223-231

Ewing WG, Studier EH, O'Farrell M (1970) Autumn fat deposition and gross body composition in three species of Myotis. Comp Biochem Physiol 36:119-129

Geiser F (1988) Reduction of metabolism during hibernation and daily torpor in mammals and birds: temperature effect or physiological inhibition? J Comp Physiol B 158:25-37

Geiser F (1996) Torpor in reproductive endotherms. In: Geiser F, Hulbert AJ, Nicol SC (eds) Adaptations to the cold: 10th international hibernation symposium. University of New England Press, Armidale, pp 81-86

Geiser F (2004) Metabolic rate and body temperature reduction during hibernation and daily torpor. Annu Rev Physiol 66:239-274

Geiser F, Ruf T (1995) Hibernation versus daily torpor in mammals and birds: physiological variables and classification of torpor patterns. Physiol Zool 68:935-966

Geiser F, Holloway JC, Körtner G, Maddocks TA, Turbill C, Brigham RMR (2000) Do patterns of torpor differ between free-ranging and captive mammals and birds? In: Heldmaier G, Klingenspor M (eds) Life in the cold. Springer, Berlin, pp 95-102
Gittleman JL, Thompson SD (1988) Energy allocation in mammalian reproduction. Am Zool 28:863-875

Grinevitch L, Holroyd SL, Barclay RMR (1995) Sex differences in the use of daily torpor and foraging time by big brown bats (Eptesicus fuscus) during the reproductive season. J Zool 235:301-309

Hayes JP, Speakman JR, Racey PA (1992) The contributions of local heating and reducing exposed surface area to the energetic benefits of huddling by short-tailed voles (Microtus agrestis). Physiol Zool 65:742-762

Heldmaier G, Neuweiler G (2004) Vergleichende Tierphysiologie Band 2. Springer, Berlin

Heldmaier G, Ruf T (1992) Body temperature and metabolic rate during natural hypothermia in endotherms. J Comp Physiol B 162:696-706

Herreid CF II (1963) Temperature regulation and metabolism in Mexican freetail bats. Science 142:1573-1574

Hock RJ (1951) The metabolic rates and body temperatures of bats. Biol Bull 101:289-299

Hollis L, Barclay RMR (2008) Developmental changes in body temperature and use of torpor by the Big Brown Bat (Eptesicus fuscus). In: Lovegrove BG, McKechnie AE (eds) Hypometabolism in animals: hibernation, torpor and cryobiology. 13th International Hibernation Symposium. University of KwaZuluNatal, Pietermaritzburg, pp 361-372

Hosken DJ, Withers PC (1997) Temperature regulation and metabolism of an Australian bat, Chalinolobus gouldii (Chiroptera: Vespertilionidae) when euthermic and torpid. J Comp Physiol B 167:7180

Hudson JW, Scott IM (1979) Daily torpor in the laboratory mouse, Mus musculus var albino. Physiol Zool 52:205-218

Kerth G (2008) Causes and consequences of sociality in bats. Bioscience 58:737-755

Kerth G, König B (1999) Fission, fusion and non-random associations in female Bechstein's bats. Behaviour 136:1187-1202

Kerth G, Reckardt R (2003) Information transfer about roosts in female Bechstein's bats: an experimental field study. Proc R Soc Lond [Biol] 270:511-515

Kerth G, Mayer F, König B (2000) Mitochondrial DNA (mtDNA) reveals that female Bechstein's bats live in closed societies. Mol Ecol 9:793-800

Kerth G, Weissmann K, König B (2001) Day roost selection in female Bechstein's bats (Myotis bechsteinii): a field experiment to determine the influence of roost temperature. Oecologia 126:1-9

Korine C, Speakman J, Arad Z (2004) Reproductive energetics of captive and free-ranging Egyptian fruit bats (Rousettus aegyptiacus). Ecology 85:220-230

Kunz TH (1987) Post-natal growth and energetics of suckling bats. In: Fenton MB, Racey P, Rayner JMV (eds) Recent advances in the study of bats. Cambridge University Press, Cambridge, pp 395420

Kurta A, Kunz TH, Nagy KA (1990) Energetics and water flux of free-ranging big brown bats (Eptesicus fuscus) during pregnancy and lactation. J Mammal 71:59-65

Lausen CL, Barclay RMR (2002) Roosting behavior and roost selection of female big brown bats (Eptesicus fuscus) roosting in rock crevices in southeastern Alberta. Can J Zool 80:1069-1076

Lausen CL, Barclay RMR (2003) Thermoregulation and roost selection by reproductive female big brown bats (Eptesicus fuscus) roosting in rock crevices. J Zool 260:235-244

Lewis SE (1993) Effect of climatic variation on reproduction by pallid bats (Antrozous pallidus). Can J Zool 71:1429-1433

McLean JA, Speakman JR (1999) Energy budgets of lactating and nonreproductive brown long-eared bats (Plecotus auritus) suggest females use compensation in lactation. Funct Ecol 13:360-372

McNab BK (1982) Evolutionary alternatives in the physiological ecology of bats. In: Kunz TH (ed) Ecology of bats. Plenum, New York, pp 151-200 
Perret M (1998) Energetic advantage of nest sharing in a solitary primate, the lesser mouse lemur (Microcebus murinus). J Mammal 79:1093-1102

R Development Core Team (2009) A language and environment for statistical computing. R Foundation for Statistical Computing, Vienna, Austria. ISBN 3-900051-07-0. http://www.R-project.org

Racey PA (1973) Environmental factors affecting the length of gestation in heterothermic bats. J Reprod Fertil Suppl 19:175-189

Racey PA, Swift SM (1981) Variation in gestation length in a colony of pipistrelle bats (Pipistrellus pipistrellus) from year to year. J Reprod Fertil 61:123-112

Ransome RD (1989) Population changes of greater horseshoe bats studied near Bristol over the past twenty-six years. Biol J Linn Soc 38:71-82

Roverud R, Chappell MA (1991) Energetic and thermoregulatory aspects of clustering behavior in the neotropical bat Noctilio albiventris. Physiol Zool 64:1527-1541

Schmid J, Ruf T, Heldmeier G (2000) Metabolism and temperature regulation during daily torpor in the smallest primate, the pygmy mouse lemur (Microcebus myoxinus) in Madagascar. J Comp Physiol B170:59-68

Sedgeley JA (2001) Quality of cavity microclimate as a factor influencing selection of maternity roosts by a tree-dwelling bat, Chalinolobus tuberculatus, in New Zealand. J Appl Ecol 38:425-438

Solick DI, Barclay RMR (2006) Thermoregulation and roosting behavior of reproductive and nonreproductive female western long-eared bats (Myotis evotis) in the Rocky Mountains of Alberta. Can J Zool 84:589-599

Speakman JR, Racey PA (1987) The energetics of pregnancy and lactation in the brown long-eared bat, Plecotus auritus. In: Fenton MB, Racey PA, Rayner JMV (eds) Recent advances in the study of bats. Cambridge University Press, Cambridge, pp 367-393

Speakman JR, Rowland A (1999) Preparing for inactivity: how insectivorous bats deposit a fat store for hibernation. Proc Nutr Soc 58:123-131
Speakman JR, Thomas DW (2003) Physiological ecology and energetics of bats. In: Kunz TH, Fenton BM (eds) Bat ecology. The University of Chicago Press, Chicago, pp 430-490

Studier EH (1981) Energetic advantages of slight drops in body temperature in little brown bats Myotis lucifugus. Comp Biochem Physiol 70:537-540

Turbill C, Geiser F (2006) Thermal physiology of pregnant and lactating female and male long-eared bats, Nyctophilus geoffrey and $N$. gouldi. J Comp Physiol B 176:165-172

Vaughan TA, O'Shea J (1976) Roosting ecology of the pallid bat Antrozous pallidus. J Mammal 57:19-42

Wang LCH (2000) Perspectives on metabolic suppression during mammalian hibernation and daily torpor. In: Heldmaier G, Klingenspor M (eds) Life in the cold. Springer, Berlin, pp 149158

Weigold H (1973) Jugendentwicklung der Temperaturregulation bei der Mausohrfledermaus, Myotis myotis (Borkhausen, 1797). J Comp Physiol A 85:169-212

Willis CKR (2006) Daily heterothermy in temperate bats using natural roosts. In: Kunz TH, Zubaid A, McCracken GF (eds) Functional and evolutionary ecology of bats. Oxford University Press, New York, pp 38-55

Willis CKR, Brigham RM, Geiser F (2006) Deep, prolonged torpor by pregnant, free-ranging bats. Naturwissenschaften 93:80-83

Willis CKR, Brigham RM (2007) Social thermoregulation exerts more influence than microclimate on forest roost preferences by a cavity-dwelling bat. Behav Ecol Sociobiol 62:97-108

Wilde CJ, Knight CH, Racey PA (1999) Influence of torpor on milk protein composition and secretion in lactating bats. J Exp Zool 284:35-41

Winchell JM, Kunz TH (1996) Day-roosting activity budgets of the eastern pipistrelle bat, Pipistrellus subflavus (Chiroptera: Vespertilionidae). Can J Zool 74:431-441

Withers PC (2001) Design, calibration and calculation for flow-through respirometry systems. Aust J Zool 49:445-461 